\title{
Teaching in a Global World: Challenges and Opportunities for Small-Sized Universities - Insights from Italy
}

\begin{abstract}
By Barbara Zagaglia*
Today's academic institutions are strongly involved in the modern globalization process. The aim of the paper is to investigate if small-sized universities face particular challenges and if they obtain some advantages or are adversely affected by the ongoing process. The focus is on Europe and, specifically, on Italy, one of the signatory countries of the Bologna Declaration, that has implemented the European international reform process. Based on official data from the Italian Ministry of University and Research, first we analyse university characteristics and then we calculate performance selected indicators that are informative of a few key aspects, such as teaching quality and internationalisation and look at student satisfaction. Results show that teaching quality in smallsized public universities is similar to that in big-sized public ones whereas small-sized private universities perform better than big-sized private ones. Attractiveness for students abroad is greater for smaller and more specialized universities, and this is especially evident for private universities. Satisfaction as well is higher for students studying in small-sized universities. However, doubts exist for the future due to the possible negative effects of the very complex and strict administrative procedures of the current organization and evaluation system.
\end{abstract}

Keywords: universities, small-sized, teaching, performance, Europe, Italy

\section{Introduction}

Globalization has been accelerating rapidly in recent decades and human activities have never been interconnected to such extent as they are today.

Academic institutions are strongly involved in the globalization process, which concerns both their two activity pillars -researching and teaching- but while in researching the process is very advanced, in teaching it lags behind (Taalas et al. 2020).

In teaching, academic institutions are concerned in globalization in a two-fold way. In the first, their current organization has been a progressive adaptation to globalization; in the second, teaching targets students who live and will be employed in a global world by moving in search of the most suitable training and which requires specific competencies.

Academic institutions are heterogeneous in a wide range of ways (for Europe see, for instance, European Commission 2011; for a world perspective see, for

*Associate Professor, Polytechnic University of Marche, Italy. 
instance, Independent Evaluation Group 2017). One significant aspect among others is their size. The aim of this paper is to investigate if size matters in the ongoing process of globalization. In particular, we are interested in investigating if small-sized universities face particular challenges and if they have some advantages or, on the contrary, if they are adversely affected by it owing to their dimension. Analysis focuses on Europe and, specifically, on Italy where, as we will show in the paper, small-sized universities are the norm. The paper is oriented to catch strategic development dimensions in higher education.

The paper is organized as follows. First, we present an overview of the literature and the study method used. Then, after briefly presenting the process of international reform of the European Union's higher education system and its current organization aiming to face the challenges of the modern and globalized world, we turn to the characteristics of the higher education system in Italy, an EU country that implemented the reform process. After that, by using data from the Italian Ministry of University and Research, we first analyse size characteristics of Italian universities and then, for each university distinguishing by university type, we calculate a few performance indicators that are informative of key aspects, such as teaching quality and internationalisation. In addition, in order to have a more comprehensive picture of the teaching performance of Italian universities by size, we look at student satisfaction with their degree programmes. Our study does not intend to evaluate the efficiency level of Italian universities but to identify some and possible strengths. Conclusions end the paper.

\section{Literature Overview}

Globalization and its impacts in higher education have been widely dealt with in literature (Geuna 1998, de Wit 2001, Spiro 2003, Dewatripont et al. 2009, Teichler 2009, Singh and Papa 2010, Renn 2012, Lemoine et al. 2017, Mense et al. 2018) as well as how to measure performance and efficiency (Higgins 1989, Carrington et al. 2005, Kuah and Wong 2011, Marope et al. 2013, Kapetaniou and Lee 2016).

Performance or efficiency has often been measured for the higher education institution activities (teaching, research, and seldom the third mission) as a whole (Avkiran 2001, Bonaccorsi et al. 2007, Faggi et al. 2018, Johnes et al. 2020) or for research activity only (Aghion et al. 2009, Veugelers and van der Ploeg 2009, Gómez et al. 2009), sometimes for or with a focus on educational activity (Avkiran 2001, Johnes 2006, Aslam 2011, De Witte and Hudrlikova 2013, Leitner et al. 2007).

As regards the size of higher education institutions, it has been investigated from various angles and in different contexts.

In the U.S., the distinction between small and big colleges and universities is quite marked (Hanstedt and Amorose 2004) and the distinction between public and private also matters. Hussar et al. (2020) showed that attending public institutions is on average cheaper than attending private for-profit institutions and especially private nonprofit ones that have the highest average tuition fees, and the highest average total and net costs of attendance (calculated for first-time, full- 
time undergraduate students attending 4-year institutions). Moreover, private universities tend to be much smaller than public universities (Bridgestock 2021). Reputation is usually better for larger universities because the most eminent scholars, the largest number of doctorates, the biggest libraries, and the most renowned research centres and laboratories are in large institutions (The Camegie Foundation for the Advancement of Teaching 1990). However, there are prestigious (and very expensive) colleges and universities, even small ones (Hanstedt and Amorose 2004).

This reputation dichotomy between large versus small universities is repeated to different extents in the rest of the world. Higher or lower reputation is, nevertheless, based on the greater weight given to some characteristics compared to others.

More and more often, opinions about university reputation are based on national and international university ranking. Compilers of general rankings apply methodologies that tend to reward large and research oriented universities but when the different strengths of universities and the criteria where they perform relatively well are taken in consideration smaller (medium sized) universities get better positions (De Witte and Hudrlikova 2013).

Small sized universities are disadvantaged in other settings as well. Bias in research grant evaluation was found for Canada (Murray et al. 2016). Differences in programme supply between small and large private universities were shown for Argentina (Balán 1990).

When efficiency was investigated, variable returns to scale have been found among universities in Australia. Findings also showed that more universities were operating at decreasing returns of scale indicating the opportunity for a downsize (Avrikan 2001).

In India, it seems that the economies of scale in the tuition of both undergraduate and postgraduate students are exhausted while the economies of scale remain unexhausted in researching. Thus, further concentration of research activity could yield benefits, whereas a greater expansion in student numbers could be obtained by stimulating the growth of the smaller universities or by establishing new institutions (Johnes et al. 2020).

In Europe, Finland, Italy, Norway, and Switzerland were considered in a study by Bonaccorsi et al. (2007). It was shown that efficiency gains change by university size and that larger units have more efficiency gains than smaller ones (conjoint teaching and research considered). Gains were found to be rather modest when the university total faculty size is less than 1,000 academics but increase faster when the number is at least up to 6,000. However, university size efficiency gain patterns differ according to disciplines.

Finally, a study on the efficiency of public universities in Italy (teaching and research considered jointly) has shown interesting results (Faggi et al. 2018). The study, which deals with twenty-five of the bigger public universities and economic efficiency (no quality indicator is applied), showed that the medium to small universities have the best efficiency performances. Belonging to this size category, the three best public universities in the whole period analysed (2006-2013) are: "Università degli Studi Gabriele D'Annunzio di Chieti e Pescara", "Università 
degli Studi di Salerno", and "Università della Calabria". The optimal scale for this subset of public universities resulted to be between 28,000 and 40,000 students enrolled. Over that size returns of scale decrease whereas below 28,000 returns of scale increase. Authors indicate that it is more efficient to start a small sized university which then grows to become medium-small sized. Over that optimal size, coordination costs have a very negative impact on the efficient use of resources.

No study, to our knowledge, simultaneously and explicitly considers the issues of globalization, performance, and university size.

\section{Methodology}

Methodologies adopted were: a) review of reforms and characteristics of the higher education system; and b) measurement of performance by indicators that were selected because more indicative of teaching quality and globalization activity. They are explained in detail later in the paper.

\section{The European Union's Higher Education System}

In 1954, European countries, aware of their common cultural identity and aiming to achieve a greater unity, signed the European Cultural Convention ${ }^{1}$. The convention states that a unique cultural base exists in Europe, which is interpreted in different nuances in each country or society, and the principle to safeguard and encourage such a culture.

In the following decades, with the strengthening of the European integration process, the enhancement of the intellectual, cultural, social and technical dimensions of the continent followed. In 1998, in The Sorbonne Joint Declaration, the education ministers of France, Germany, Italy, and the United Kingdom asserted the need of creating a union of knowledge in Europe and engaged in the harmonization of the architecture of the European higher education system calling on other European countries to join the project.

The following year, twenty-nine European education ministers met and signed The Bologna Declaration committing themselves to launch convergent national reforms on the base of common key values - freedom of expression, autonomy for institutions, independent student unions, academic freedom, free movement of students and staff. Since then a process of international reform of the European Union's higher education system - The Bologna Process - has developed ${ }^{2}$.

The main goal was the creation of the European Higher Education Area (EHEA), a common area for promoting the mobility of students, teachers, researchers, and administrative staff and the mutual recognition of qualification. A

${ }^{1}$ ETS n.018/1954.

${ }^{2}$ All the declarations related to the Bologna Process are available at: http://www.ehea.info/page-mi nisterial-declarations-and-communiques. 
further aim of EHEA was to increase the global competitiveness of the European higher education system, at a time when the movement of goods, money, and people was rapidly spreading across the globe. Established in 2010, EHEA should be accomplished by 2025. At present, the number of EHEA member states is forty-eight and includes EU and non-EU member states ${ }^{3}$.

A European qualification framework was set, which consists of three cycles of higher education qualification based on the European Credit Transfer and Accumulation Systems (ECTS). The system of credits, indeed, calculated on study time, allows students to validate credits acquired in a different European university, thus promoting mobility. The first (undergraduate) cycle usually awards a bachelor's degree and requires 180 to 240 ECTS credits; the second (graduate) cycle usually awards a master's degree and requires 60 to 120 ECTS credits; the third cycle, which awards a doctorate degree, is not provided with a concrete ECTS range 4 .

Consistently with the purpose of creating an area of European higher education, the development of comparable criteria and methodologies of quality assurance has been promoted.

The European quality assurance system is based on common standards and guidelines, the "Standards and Guidelines for Quality Assurance in the European Higher Education Area" (ESG), introduced in 2005 and updated in $2015^{5}$. It is founded on a constructive contest between external evaluation (External Quality Assurance) and self-evaluation (Internal Quality Assurance). The bodies appointed to carry out external evaluation activities usually have the nature of agencies, national or international, one or more organizations. The European Quality Assurance Register for Higher Education (EQAR) established in 2008 lists the quality assurance agencies that substantially comply with the $\mathrm{ESG}^{6}$.

For detailed information on the European Union's higher education system see Agenzia Nazionale di Valutazione del sistema Universitario e della Ricerca (2018), EHEA official website ${ }^{7}$, and European Commission/EACEA/Eurydice (2018). For a discussion on the Sorbonne and Bologna Declaration see de Wit (2000).

\footnotetext{
${ }_{3}^{3}$ Membership is open to the European Cultural Convention members. Full list of member states is available at: http://www.ehea.info/page-full_members.

${ }^{4}$ A clear presentation of the three cycle system is available at http://www.ehea.info/page-three-cyc le-system.

${ }^{5}$ Available at http://www.ehea.info/page-standards-and-guidelines-for-quality-assurance.

${ }^{6}$ https://www.eqar.eu/.

${ }^{7}$ http://www.ehea.info/.
} 


\section{Higher Education System and Universities in Italy}

\section{The Italian Higher Education System}

Italy is a signatory country of the Bologna Accord. As the Bologna process does not have the status of EU legislation, there is no obligation for signatory states and participation is voluntary. Moreover, when participating in the process, because of the principle of autonomy, states can implement reforms by tailoring their higher education systems to the peculiarities of their society and labour market needs and to their particular objectives. This also occurred in Italy.

In Italy, higher education is divided into three phases in line with the Qualification Framework for the European Higher Education Area from $1999^{8}$.

Beyond a degree course in the first cycle (3 year duration, equivalent to 180 ECTS) and a degree course in the second cycle (2 year duration, equivalent to 120 ECTS), in some universities and for some subjects (law, medicine, pharmacology) there are single-cycle master programmes lasting 5 or 6 years and requiring 300 or 360 ECTS.

A first and a second level specializing master course can also be provided respectively in the second and third cycle, for a minimum of 60 credits each. The first level specializing master course is available in some universities under their autonomous responsibility with the aim of increasing students' professional education. This qualification is not part of the European university system.

A post-graduate diploma course in the third cycle aims to provide the knowledge and skills required for carrying out the functions required by particular professional activities. The course lasts at least 2 years. Finally, in the third cycle the doctorate programme lasts 3 years.

As regards supervision and quality standards assurance, in Italy it is entrusted to a sole body, a national independent agency - "Agenzia Nazionale di Valutazione del Sistema Universitario e della Ricerca" (ANVUR) - established in 2006 (D.L. n.262/2006) and in force since $2011^{9}$.

ANVUR applies the "Standards and guidelines for quality assurance in the European higher education area" and evaluates all kinds of activities (teaching, research, administration, and third mission) at all levels (degree and doctoral programme, department, university/institute). European standards and guidelines are applied as pre-requisites for the initial and periodic accreditation and together with quantitative indicators for annual monitoring and self-evaluation according to an assurance quality model named AVA ${ }^{10}$. Actually, ANVUR is an affiliate but not yet member of EQAR and it is not in its list. The procedures for accreditation by ENQUA are ongoing.

\footnotetext{
${ }^{8}$ D.M. n.509/1999. Many further efforts were made to improve and adapt the higher education system. A successive important reform that is worth mentioning is L. n.240/2010. ${ }^{9}$ https://www.miur.gov.it/anvur.

${ }^{10}$ Autovalutazione - Valutazione periodica - Accreditamento (self-evaluation - periodical evaluation - accreditation).
} 
The Italian quality assurance system involves ANVUR for external evaluation, universities for self-evaluation, and also the Evaluation Unit, which is a third party that acts as a liaison between the two and that has no correspondence in the European evaluation system.

At the moment, the Italian quality assurance system has yet to be completed with regard to the non-university side of the higher education system, i.e., AFAM Institutes - the higher education institutes in art sectors - to third mission and to administrative activities.

Public funding to universities and research institutes depends on the agency's evaluation, stimulating higher education institutes to improve quality.

For detailed information see Agenzia Nazionale di Valutazione del sistema Universitario e della Ricerca (2018), Rugge (2019), Processo di Bologna website ${ }^{11}$, TREELLLE (2017).

Currently, the Italian higher education system consists of 97 accredited public and private universities and 145 accredited public and private AFAM Institutes (MIUR data ${ }^{12}$ ). Private universities include distance learning universities, which are simply called and known as "on-line" universities ${ }^{13}$.

\section{The Italian Universities}

As regards universities, according to the Italian University and Research Ministry data, in a.y. 2018-2019 (at the time of writing the last concluded academic year) the total number of students enrolled was slightly more than 1,700 million. After having witnessed a decrease because of the economic crisis (Agenzia Nazionale di Valutazione del sistema Universitario e della Ricerca 2018), the number has increased in recent years. In particular, in the last triennium it increased by 25,000 from a.y. $2016-2017$ to a.y. 2017-2018 and by 26,000 from a.y. 20172018 to a.y. 2018-2019.

Students are mostly enrolled in public universities but the greatest increase has occurred in private universities, especially in on-line ones. For the latter, the increase was over $20 \%$, ten times the increase in public universities.

There is a great variability in size. The smallest university has only 81 students enrolled, the biggest slightly more than 100,000 .

The average university size is 18,715 students. The biggest universities are usually public, their average size numbering almost 24,600 students whereas the average size of private universities is approximately 7,200 , less than one third of the average size of public universities.

Total and average number of students enrolled by university type in recent years is shown in detail in Table 1.

\footnotetext{
${ }^{11}$ http://www.processodibologna.it/.

${ }^{12} \mathrm{https} / / / \mathrm{www}$. miur.gov.it/web/guest/sistema_universitario.

${ }^{13}$ In Italy, e-learning was first regulated in 2003 by an inter-ministerial decree, which has also started on-line universities (Ministero dell'Istruzione, dell'Università e della Ricerca 2010).
} 
From our calculations, 58 universities out $92(63 \%)$ result as having a below average number of students. These can be defined as small.

Small universities are fairly evenly distributed over the national territory, on-line universities excluded. Indeed, accredited on-line universities are a distinguishing group of universities: they are a very small group $(n=11)$, highly heterogeneous in the number of students enrolled (from a minimum of 81 to a maximum of 39,282), and prevalent in Central and Southern Italy.

Table 1. Students Enrolled by University Type

\begin{tabular}{|c|c|c|c|}
\hline University type & $\begin{array}{c}\text { A.Y. } \\
\text { 2016-2017 }\end{array}$ & $\begin{array}{c}\text { A.Y. } \\
2017-2018\end{array}$ & $\begin{array}{c}\text { A.Y. } \\
2018-2019\end{array}$ \\
\hline & \multicolumn{3}{|c|}{ Total number of students enrolled } \\
\hline Public & $1,491,483$ & $1,497,235$ & $1,500,030$ \\
\hline Private & 179,156 & 198,493 & 221,760 \\
\hline Traditional & 101,626 & 104,842 & 108,096 \\
\hline On-line & 77,530 & 93,651 & 113,664 \\
\hline \multirow[t]{2}{*}{ All } & $1,670,639$ & $1,695,728$ & $1,721,790$ \\
\hline & \multicolumn{3}{|c|}{ Average number of students enrolled } \\
\hline Public & $\begin{array}{c}24,451 \\
(61)\end{array}$ & $\begin{array}{c}24,545 \\
(61)\end{array}$ & $\begin{array}{c}24,591 \\
(61)\end{array}$ \\
\hline Private & $\begin{array}{c}5,972 \\
(30)\end{array}$ & $\begin{array}{c}6,616 \\
(30)\end{array}$ & $\begin{array}{c}7,154 \\
(31)\end{array}$ \\
\hline Traditional & $\begin{array}{c}5,349 \\
(19)\end{array}$ & $\begin{array}{c}5,518 \\
(19)\end{array}$ & $\begin{array}{c}5,405 \\
(20)\end{array}$ \\
\hline On-line & $\begin{array}{c}7,048 \\
(11)\end{array}$ & $\begin{array}{c}8,514 \\
(11)\end{array}$ & $\begin{array}{c}10,333 \\
(11)\end{array}$ \\
\hline All & $\begin{array}{c}18,359 \\
(91)\end{array}$ & $\begin{array}{c}18,634 \\
(91)\end{array}$ & $\begin{array}{c}18,715 \\
(92)\end{array}$ \\
\hline
\end{tabular}

Note: In parenthesis the total number of universities.

Source: Our elaboration on MIUR data (MIUR, Ufficio Statistica e Studi, available at http://ustat. miur.it/).

\section{Performance of Italian Universities}

The Italian university system is compulsorily evaluated by ANVUR, the National Agency for Evaluation of Universities and Research Institutes, mainly by a large set of fixed quantitative indicators and complex and strict procedures ${ }^{14}$. The biannual report that the agency prepares does not answer our research questions because the data reported on the different aspects subject to evaluation follow a system perspective.

Individual universities can be evaluated on a voluntary basis by international agencies (THE, QS World University Ranking, and ARWU among the best known). However, they apply different and not clearly defined data, methods, and

\footnotetext{
${ }^{14}$ Thirty indicators for the annual monitoring and internal control (Rugge 2019).
} 
indicators (De Witte and Hudrlikova 2013, Rugge 2019). As a consequence, the different international ranks do not consider all universities and rankings are not comparable. In this case as well, it is not possible to deduce any robust conclusion on the performance of small-sized universities.

To answer the research question, we measured the performance of each Italian university by calculating selected indicators on teaching quality and internationalization. We applied them to official data provided by the Italian University and Research Ministry (MIUR, Ufficio Statistica e Studi, available at http://ustat.miur.it/). Last available data refer to a.y. 2018-2019. High schools, which provide only the third cycle of higher education and have a special organization, are not included either in the dataset or in our analysis.

\section{Teaching Quality}

A teaching quality indicator we considered is the ratio between the number of students enrolled and the size of the teaching staff. High levels of the indicator can indicate low quality of teaching presuming that students can be followed and supported better in their learning when classes or groups are small. As the teaching staff consists of both permanent and fixed-term teachers and researchers, we calculated two different indicators: one considers only tenured professors ${ }^{15}$, the other considers all teachers and researchers ${ }^{16}$. We calculated both indicators distinguishing between public and private universities. We further distinguished private universities between traditional and on-line ones (there are no on-line public universities in Italy).

First, we analysed how universities are staff equipped. Results show that Italian universities are very differently equipped with permanent and fixed-term teaching staff and situations vary by university type. When public universities are considered, the percentage of tenured out of all the teaching and research staff is high, on average over $50 \%$ (Figure 1).

\footnotetext{
${ }^{15}$ Tenured professors' category includes assistant professors, associate professors, and full professors. ${ }^{16}$ The group includes tenured professors, fixed-term researchers, research fellows, contract researchers and contract teachers.
} 
Figure 1. Percentage of Tenured Professors of All the Teaching Staff Members Public Universities, Italy, a.y. 2018-2019

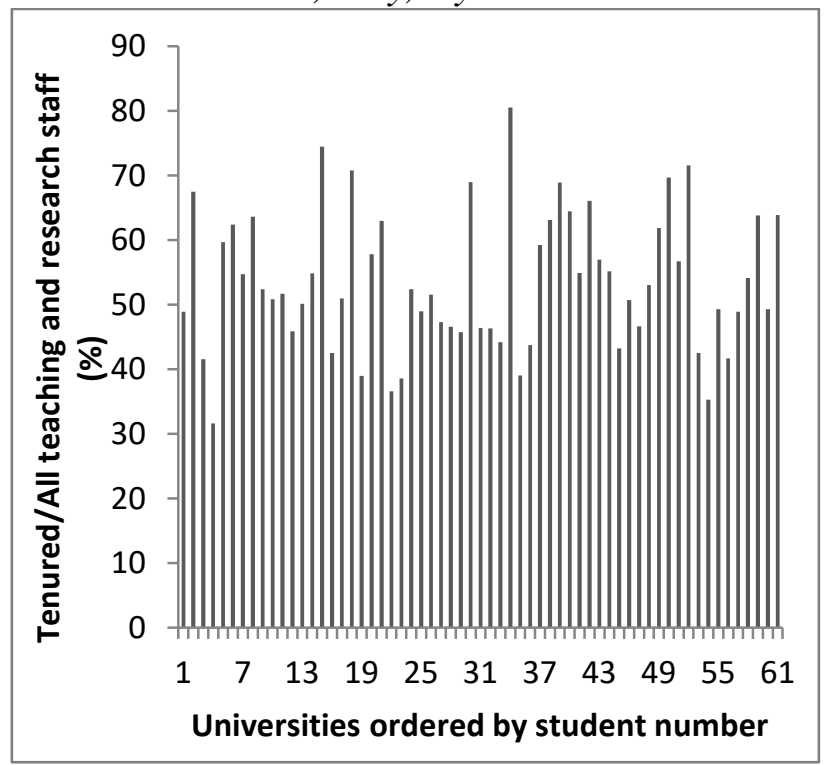

Source: Our elaboration on MIUR data.

In private universities, the use of teaching contracts and fixed-term research staff is widespread up to the point that the smallest traditional and the smallest online universities have no tenured professors. The percentage of tenured professors is lower and the situation is more heterogeneous than in public universities. In the case of traditional universities, the percentage of tenured professors averages $22.9 \%$ ranging from 0 to $62 \%$ (Figure 2).

Figure 2. Percentage of Tenured Professors of All the Teaching Staff Members Traditional Private Universities, Italy, a.y. 2018-2019

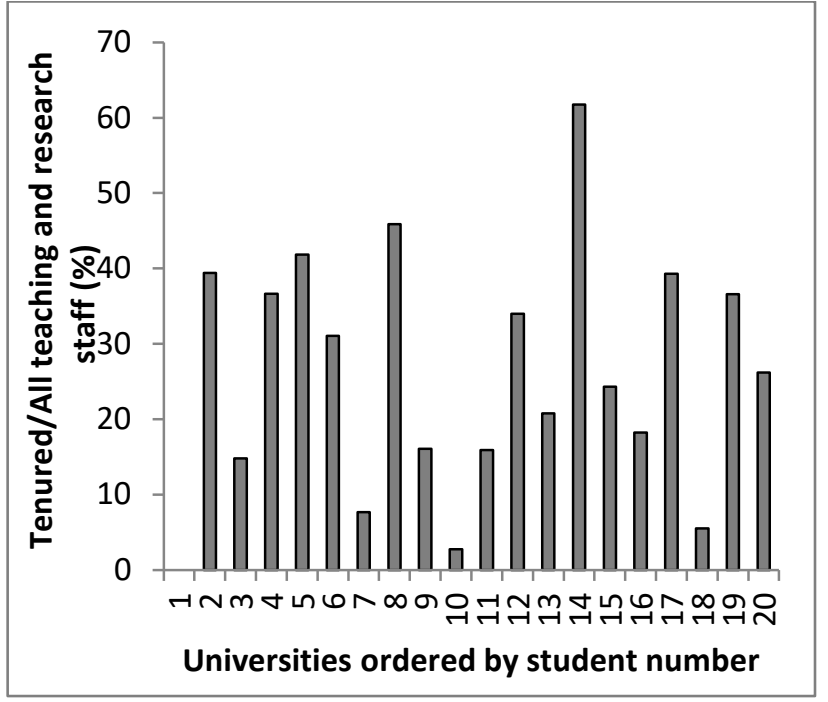

Source: Our elaboration on MIUR data. 
For on-line private universities the situation worsens (Figure 3). Indeed, the percentage of tenured professors is less than in traditional private universities, the average being $14.1 \%$.

Figure 3. Percentage of Tenured Professors of All the Teaching Staff Members On-Line Private Universities, Italy, a.y. 2018-2019

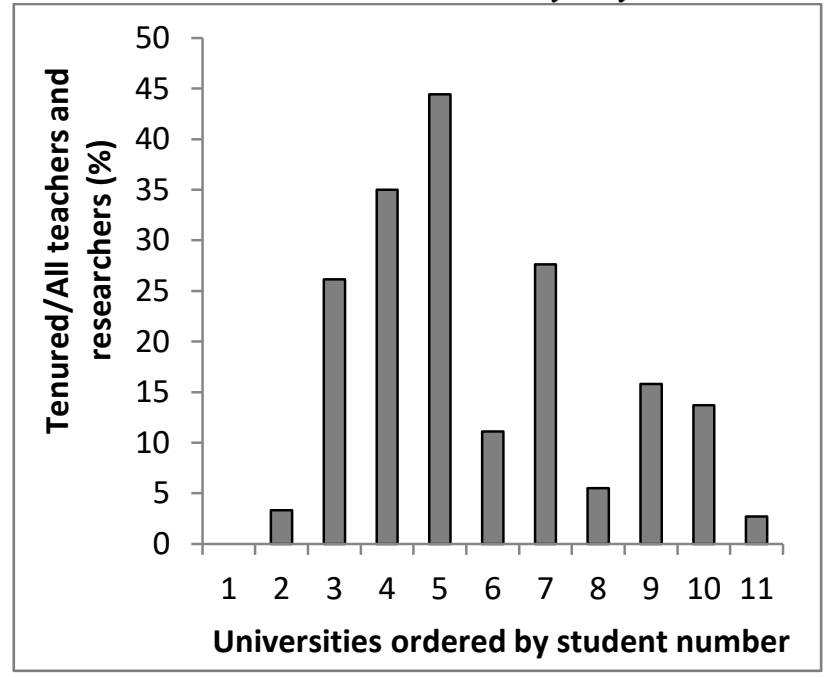

Source: Our elaboration on MIUR data.

When we analysed teaching performance, we found that, for public universities, it is high whatever indicator is considered: the number of students enrolled for each tenured professor is on average 32.3 and decreases to 18.1 when both permanent and fixed-term teachers and researchers are considered. As regards size, no clear correlation with teaching quality is evident (Figure 4).

Figure 4. Number of Students Enrolled to Teacher - Public Universities, Italy, a.y. 2018-2019

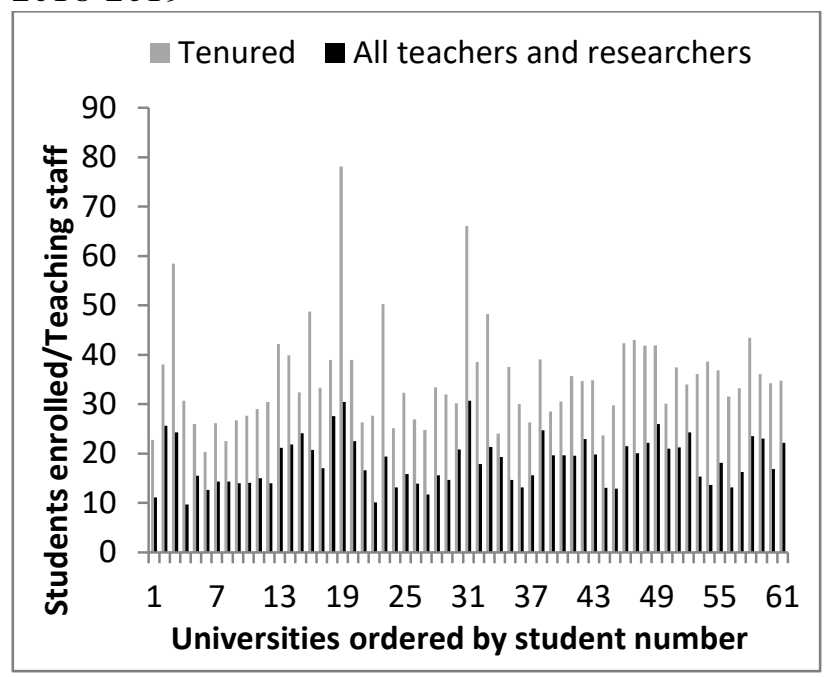

Source: Our elaboration on MIUR data. 
When we look at private universities, in the case of traditional universities, with the only exception of a few universities, the indicator shows better teaching quality for smaller-sized universities, whatever staff set is considered (Figure 5).

Figure 5. Number of Students Enrolled to Teacher - Traditional Private Universities, Italy, a.y. 2018-2019

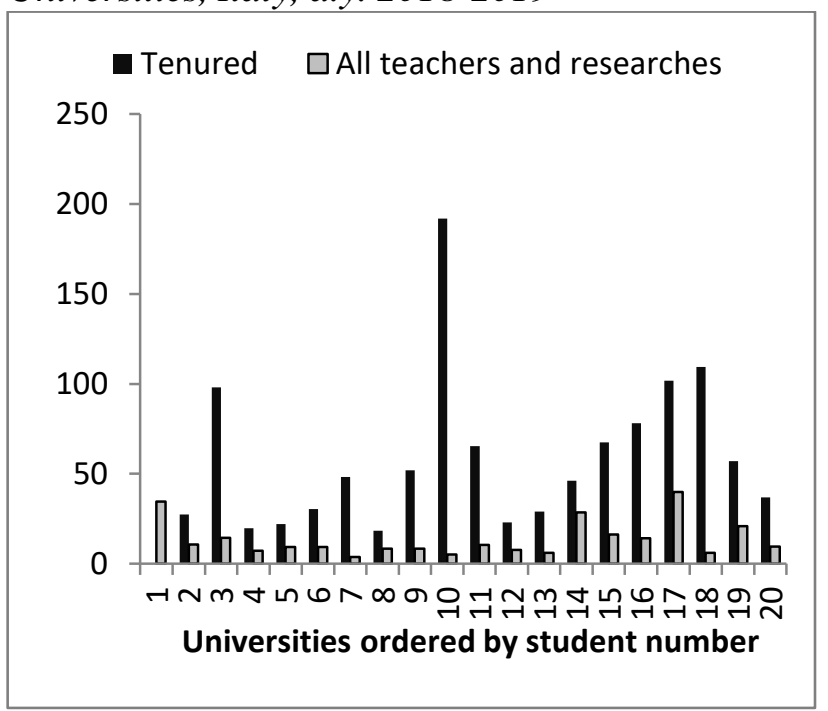

Source: Our elaboration on MIUR data.

For on-line universities, the number of students enrolled for each tenured professor is very high (on average 472.6 students per professor). Better teaching quality is evident when all teaching staff members are considered (on average 63.3 students for each teaching staff member) and there is a tendency for the number to be lower for smaller universities (Figures 6 and 7).

Figure 6. Number of Students Enrolled to Tenured Teacher - On-Line Private Universities, Italy, a.y. 2018-2019

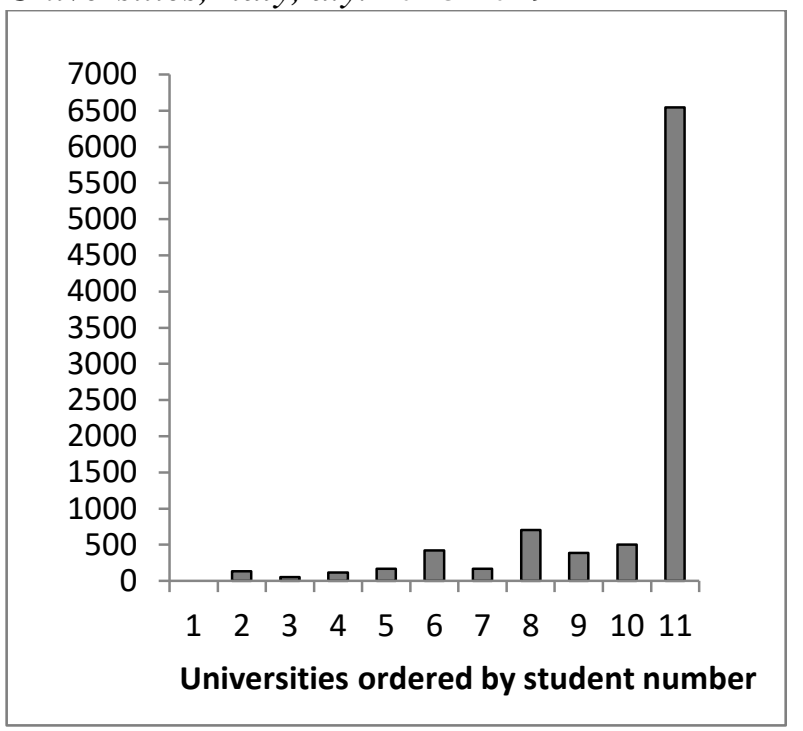

Source: Our elaboration on MIUR data. 
Figure 7. Number of Students Enrolled to Teaching Staff Member - On-Line Private Universities, Italy, a.y. 2018-2019

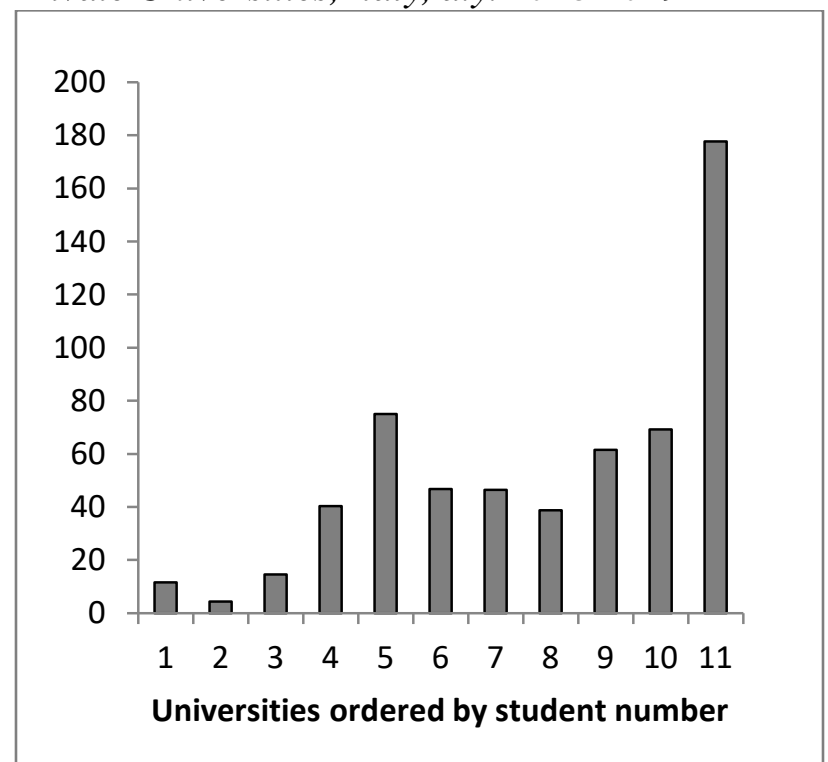

Source: Our elaboration on MIUR data.

\section{Internationalization}

One aspect of internationalization is attractiveness for students from abroad. Since in the case of short-term movements - for the attendance of one or two semesters without enrolling - students' choice of country and university can be strongly influenced by a city's fame, we focus on long-term movements of students for the enrolment in a degree programme. In the latter case, we expect that the universities rather than the characteristics of a place play a major role.

The variable we consider is the number of foreign students enrolled and its ratio to total students enrolled ${ }^{17}$.

As a whole, Italian universities are not very attractive to foreign students. When we consider public universities, the percentage of foreign students is on average 5.4 and there is neither a clear positive nor a clear negative correlation between size and attractiveness. However, some universities have high or very high percentages of foreign students enrolled both among small and among big universities (Figure 8).

\footnotetext{
${ }^{17}$ Available data do not distinguish between resident foreigners and non resident foreigners. Better information would come from the number of students enrolled with qualifications obtained abroad but in this case data are not available at individual (university) level.
} 
Figure 8. Percentage of Foreign Students Enrolled in Public Universities - Italy, a.y. 2018-2019

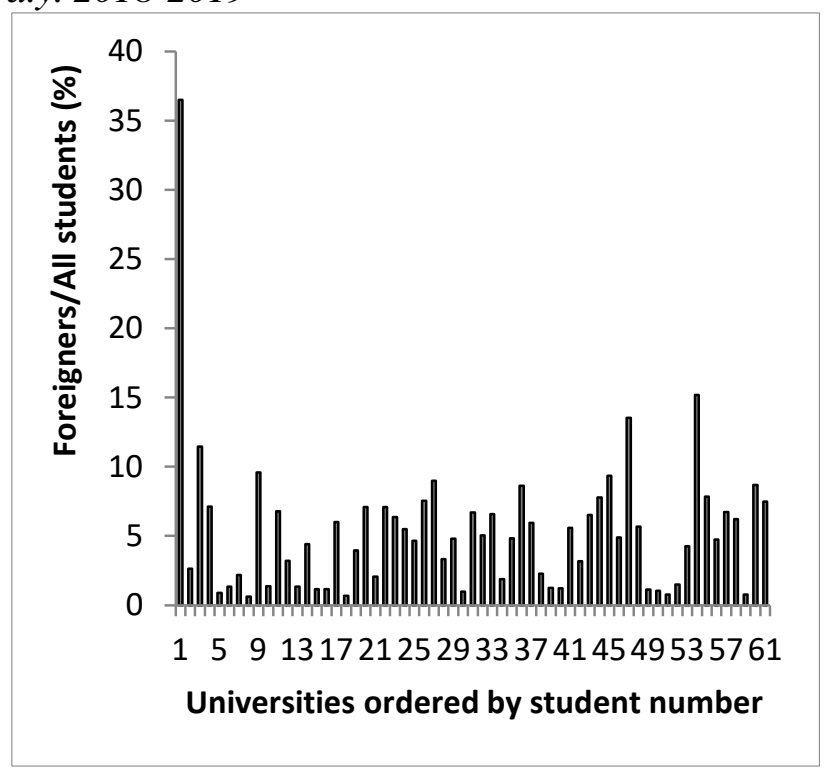

Source: Our elaboration on MIUR data.

The smallest public university, the "Università per stranieri di Perugia", stands out. It is involved in teaching, research activities and diffusion of the Italian language and civilisation and recruits around 1,000 students, 36\% of which are foreigners. Another small public university (around 2,200 students enrolled) that has a significant share of foreign students $(11 \%)$ operates in the same field ("Università per stranieri di Siena"), while the small ancient university of Camerino ("Università degli studi di Camerino") operates in many different scientific fields and has around 6,600 students enrolled and 10\% of them are foreigners.

Among the bigger universities two polytechnics have very good attractiveness. They are "Politecnico di Milano" (around 45,000 students enrolled, 15\% foreigners) and "Politecnico di Torino" (around 32,000 students enrolled, 14\% foreigners).

For traditional private universities the percentage increases slightly to an average of 5.6 and greater attractiveness is evident for small-sized universities. The correlation between university size and the percentage of foreign students enrolled is definitely negative (Figure 9). 
Figure 9. Percentage of Foreign Students Enrolled in Traditional Private Universities - Italy, a.y. 2018-2019

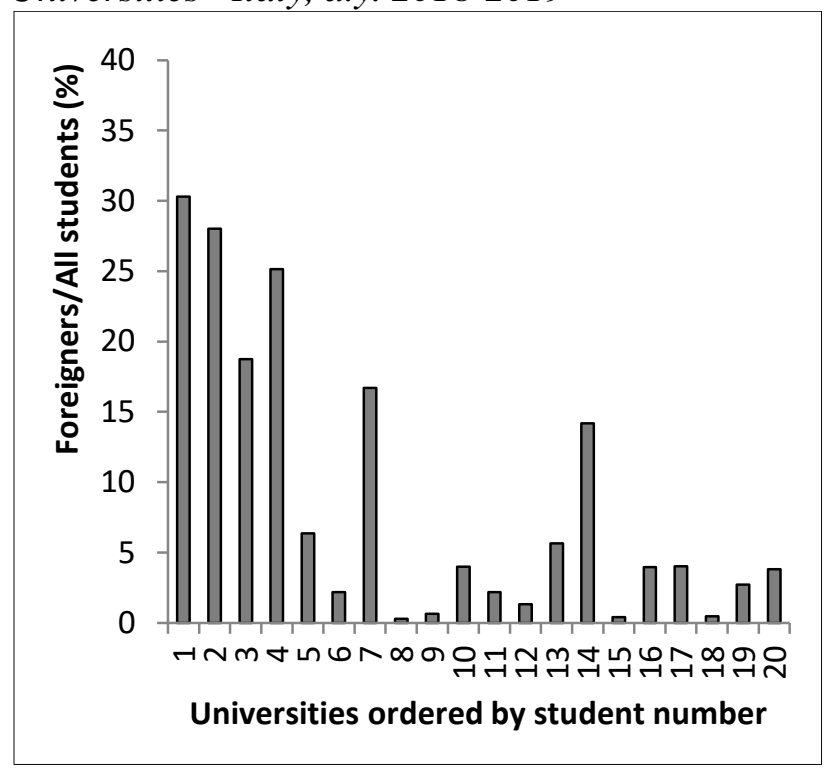

Source: Our elaboration on MIUR data.

Particularly attractive are two traditional private universities in the field of health and medical sciences (the youngest and smallest traditional private university, "Saint Camillus International University of Health", and the "Humanitas University"), the only university in gastronomic sciences ("Università di Scienze Gastronomiche"), and a university in Italian language and civilization ("Università per stranieri 'Dante Alighieri' di Reggio Calabria"), respectively with 208, 947, 357 , and 784 students enrolled and $30 \%, 25 \%, 28 \%$, and $19 \%$ of foreigners.

Other small traditional private distinguished universities are the "Libera Università Mediterranea Jean Monnet" (17\% of foreign students), which operates in law, economics, and management, and the "Libera Università della Sicilia Orientale 'Kore' di Enna"(14\% of foreign students), which operates in a vast and varied range of fields.

The situation is different for private on-line universities, the attractiveness of which is very low, without exceptions. The percentage of foreign students enrolled decreases significantly to an average of 1.9 (Figure 10). This is not surprising because of their nature and the students they target (young and adult workers, people with disabilities, and all those who have some kind of difficulty in attending in person $)^{18}$.

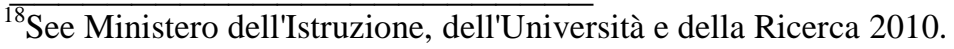


Figure 10. Percentage of Foreign Students Enrolled in On-Line Private Universities - Italy, a.y. 2018-2019

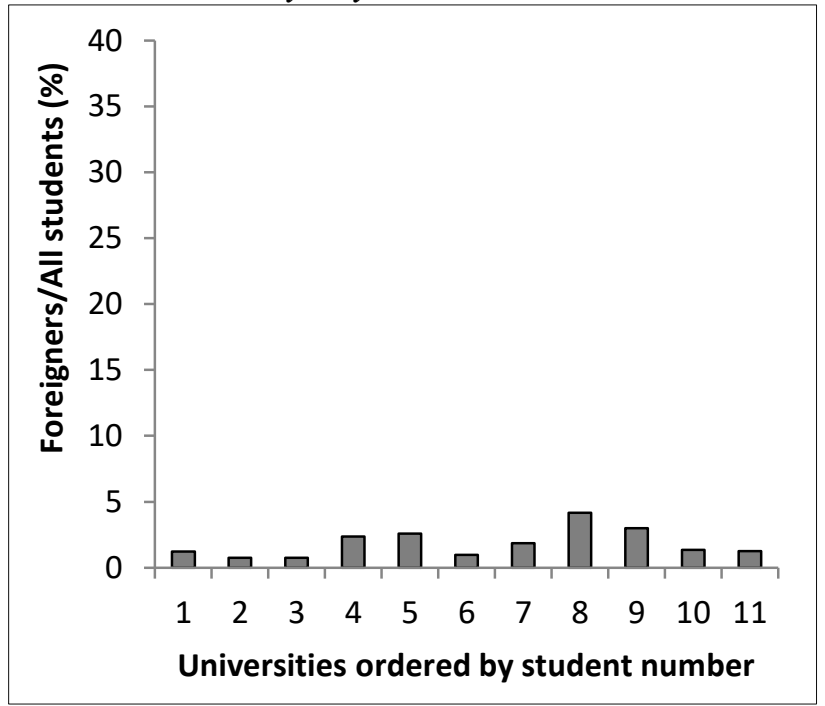

Source: Our elaboration on MIUR data.

\section{Student Satisfaction}

Student satisfaction is an additional important factor in assessing the quality of a university and as such it is an issue dealt with in the European standards and guidelines for quality assurance and is considered in the quality system implemented by ANVUR.

Opinions of students, graduands, and graduates are collected for individual courses within each degree programme but the national evaluation system has not provided universities with a standardized procedure and strict indications for the publication of results. This procedure and content heterogeneity is an obstacle in constructing homogeneous and comparable indicators.

Hence, we refer to data from an annual survey conducted by AlmaLaurea, an interuniversitary consortium supported by the Italian Ministry of Education, University, and Research, as they are provided by ANVUR (Agenzia Nazionale di Valutazione del sistema Universitario e della Ricerca 2018). Data refer to students who graduated in $2017^{19}$.

The questionnaire includes a lot of information about study experience gathered in the imminence of obtaining qualification. In particular, students at the end of their studies were asked about their satisfaction on their degree programme.

In 2017, students answered showing different levels of satisfaction and positive on the whole. The percentage of students who said they were very satisfied is very

\footnotetext{
${ }^{19}$ Survey was conducted by AlmaLaura statistical office, which is member of SISTAN, the national statistic system. Survey involved 72 universities and two high schools (the latter are not included in the data) and accounted for approximately $90 \%$ of Italian graduates. Respondents were 276,195 and the response rate was $92.4 \%$ (Consorzio Universitario AlmaLaurea 2018). On-line universities are not consortium members.
} 
high, especially in the case of small-sized universities, up to $70 \%$ for students who graduated in small but private universities (medium-dark blue bars in Figure 11).

Figure 11. Graduands in 2017 by Overall Satisfaction on Degree Programme and University (Percentages) - Italy

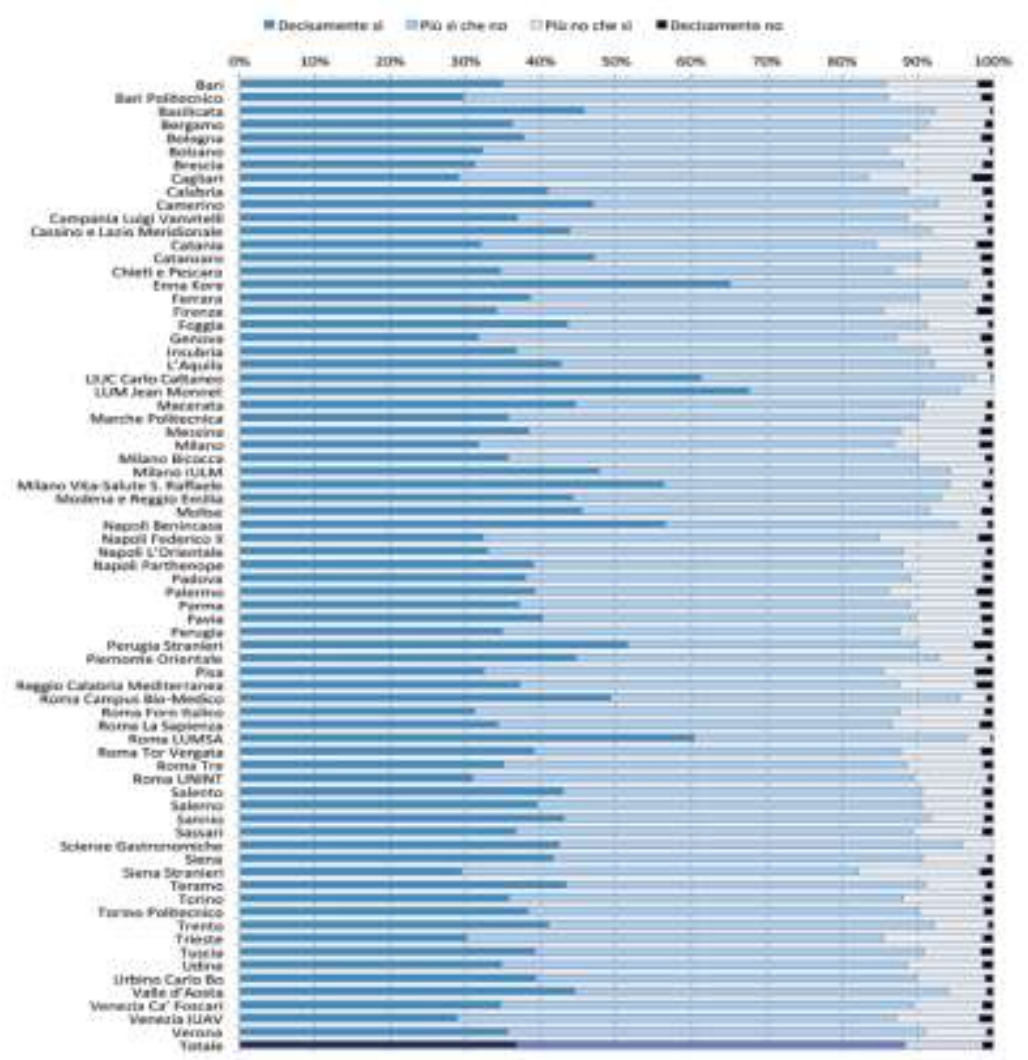

Source: Agenzia Nazionale di Valutazione del sistema Universitario e della Ricerca (2018).

To fix the results, we observe that more than $50 \%$ of graduands said they were very satisfied with having attended a degree programme in the "Libera Università della Sicilia Orientale 'Kore' di Enna", "Università 'Carlo Cattaneo' - LIUC", "Libera Università Mediterranea Jean Monnet", "Libera Università Vita-Salute S.Raffaele di Milano", "Università degli Studi Suor Orsola Benincasa di Napoli", "Università per stranieri di Perugia", and the "Libera Università Maria SS.Assunta - LUMSA di Roma".

It is a matter of seven very small universities - six private and one public with 1,000 to 8,200 students enrolled, operating in very different fields of knowledge and geographical areas and that only partially correspond to the outstanding small universities we mentioned in previous paragraphs.

\section{Conclusions}

We studied the Italian university system in the context of the international reform of European higher education. We considered all the universities and focused on their performance (not on their efficiency). We measured teaching 
performance looking at some characteristics that represent key aspects in globalization.

We showed that small-sized universities are a pillar of the Italian university system. They make up the larger part of universities and usually have good teaching performances.

Findings showed that, whereas teaching quality is a standard for public universities, and does not depend on size, small-sized private universities perform better than big-sized ones; attractiveness for students abroad is greater for smaller and more specialized universities, in particular those that operate in the typical Italian excellence sectors, and this is especially evident for the private ones; students' satisfaction is higher when they study in small-sized universities and it significantly increases in the case of private institutions.

In Italy, small-sized universities are integrated in the current learning global market. Their global and international orientation can be a further stimulus for the economic and social progress of the territories in which they are located and which mainly consist of small cities and small firms. Therefore, they have an important role in the cultural, economic, and social development of local, national and international populations. Their key role should be adequately acknowledged and they should be appropriately supported. Appropriate actions should be implemented for the proper promotion of small-sized universities among the potential buyers of their outputs (students, firms, institutions).

Finally, from our study, under the present conditions, some doubts arise about sustainability in the future. Indeed, due to the very complex and strict administrative procedures of the current organization and evaluation system, it is reasonable to think that the workload on teachers, researchers, and administrative staff is heavier for smaller than for bigger universities, given their lower quantitative human resource endowments. This could lead to some negative consequences in the years to come. Corrective actions towards simplification and organizational improvement should be implemented.

\section{References}

Agenzia Nazionale di Valutazione del sistema Universitario e della Ricerca (2018) Rapporto Biennale sullo Stato del Sistema Universitario e della Ricerca 2018. (Biennial report on the state of the university and research system 2018). Retrieved from: https://www.anvur.it/rapporto-biennale/rapporto-biennale-2018/. [Accessed 21May 2020]

Aghion P, Dewatripont M, Hoxby C, Mas-Colell A, Sapir A (2009) Why reform Europe's universities? In M Dewatripont, F Thys-Clément, L Wilkin (eds.), Higher Education in a Globalized World: Governance, Competition and Performance, 51-63. Bruxelles: Editions de l'Université de Bruxelles.

AlmaLaurea (2018) XX Indagine. Profilo dei laureati 2017. Rapporto 2018. (XX Investigation. Profile of 2017 graduates. 2018 report). Bologna: Consorzio Universitario AlmaLaurea.

Aslam HD (2011) Performance evaluation of teachers in universities: contemporary issues and challenges. Journal of Education and Social Research 1(2): 11-31. 
Avkiran N (2001) Investigating technical and scale efficiencies of Australian universities through data envelopment analysis. Socio-Economic Planning Sciences 35(1): 57-80.

Balán J (1990) Private universities within the Argentine higher educational system, trends and prospects. Higher Education Policy 3(2): 13-17.

Bonaccorsi A, Daraio C, Räty T, Simar L (2007) Efficiency and university size: disciplinewise evidence from European universities. MPRA Paper 10265. Munich, Germany: University Library of Munich.

Bridgestock L (2021) How much does it cost to study in the US? Retrieved from: https:// www.topuniversities.com/student-info/student-finance/how-much-does-it-cost-studyus. [Accessed 22 March 2021]

Carrington R, Coelli T, Prasada Rao DS (2005) The performance of Australian universities: conceptual issues and preliminary results. Economic Papers: A Journal of Applied Economics and Policy 24(2): 145-163.

Consorzio Universitario AlmaLaurea (2018) XX Indagine. Profilo dei laureati 2017. Rapporto 2018. (XX Investigation. Profile of 2017 graduates. 2018 report). Bologna: AlmaLaurea.

De Wit H (2000) The Sorbonne and Bologna declarations on European higher education. International Higher Education 18(Mar): 8-9.

De Wit JWM (2001) Internationalisation of higher education in the United States of America and Europe. Amsterdam: in eigen beheer.

De Witte K, Hudrlikova L (2013) What about excellence in teaching? A benevolent ranking of universities. Scientometrics 96(1): 337-364.

Dewatripont M, Thys-Clément F, Wilkin L (Eds.) (2009) Higher Education in a globalized world: governance, competition and performance. Bruxelles: Editions de l'Université de Bruxelles.

European Commission (2011) On recent developments in European high education systems. Brussels: European Commission.

European Commission/EACEA/Eurydice (2018) The European higher education area in 2018: Bologna process implementation report. Luxembourg: Publication Office of the European Union.

Faggi F, Gregori GM, Madoni S (2018) Indagine sull'efficienza delle università pubbliche italiane. (Survey on the efficiency of Italian public universities). Economia e Politica $16(2)$.

Geuna A (1998) The internationalisation of European universities: a return to medieval roots. Minerva 36(3): 253-270.

Gómez I, Bordons M, Fernández MT, Morillo F (2009) Structure and research performance of Spanish universities. Scientometrics 79(1): 131-146.

Hanstedt P, Amorose T (2004) Guest editors' introduction: the idea of the small school: beginning a discussion about composition at small colleges and universities. Composition Studies 32(2): 13-29.

Higgins JC (1989) Performance measurement in universities. European Journal of Operational Research 38(3): 358-368.

Hussar B, Zhang J, Hein S, Wang K, Roberts A, Cui J, et al. (2020) The Condition of Education 2020. NCES 2020-144. Washington, D.C.: U.S. Department of Education. National Center for Education Statistics.

Independent Evaluation Group (2017) Higher education for development: an evaluation of the World Bank group's support. Washington, D.C.: World Bank Group.

Johnes J (2006) Measuring teaching efficiency in higher education: an application of data envelopment analysis to economics graduates from UK universities 1993. European Journal of Operational Research 174: 443-456. 
Johnes G, Johnes J, Virmani S (2020) Performance and efficiency in Indian universities. Socio-Economic Planning Sciences: 100834. [In Press]

Kapetaniou C, Lee SH (2016) A framework for assessing the performance of universities: the case of Cyprus. Technological Forecasting and Social Change 123: 169-180.

Kuah CT, Wong KY (2011) Efficiency assessment of universities through data envelopment analysis. Procedia Computer Science 3: 499-506.

Leitner K, Prikoszovits J, Schaffhauser-Linzatti M, Wagner K (2007) The impact of size and specialisation on universities' department performance: a DEA analysis applied to Austrian universities. Higher Education 53(4): 517-538.

Lemoine PA, Jenkins WM, Richardson MD (2017) Global higher education: development and implications. Journal of Education and Development 1(1): 58-71.

Marope PTM, Wells PJ, Hazelkorn E (Eds.) (2013) Rankings and accountability in higher education: uses and misuses. Paris: UNESCO Publishing.

Mense EG, Lemoine PA, Garretson CJ, Richardson MD (2018) The development of global higher education in a world of transformation. Journal of Education and Development 2(3): 47-60.

Ministero dell'Istruzione, dell'Università e della Ricerca, Comitato nazionale per la valutazione del sistema universitario (2010) Analisi della situazione delle Università Telematiche. (Analysis of the situation of the telematic universities). Doc 04/10 MIUR. Ministero dell'Istruzione, dell'Università e della Ricerca.

Murray DL, Morris D, Lavoie C, Leavitt PR, MacIsaac H, Masson MEJ, et al. (2016) Bias in research grant evaluation has dire consequences for small universities. PLOS ONE 11(6): e0155876.

Renn J (Ed.) (2012) The Globalization of Knowledge in History. epubli GmbH.

Rugge F (Ed.) (2019) L'internazionalizzazione della Formazione Superiore in Italia. Le Università. (The internationalization of higher education in Italy. The universities). Fondazione CRUI. Retrieved from: https://www.crui.it/ima ges/crui-rapporto-interdigitale.pdf. [Accessed 24 April 2020]

Singh N, Papa R (2010) The impacts of globalization in higher education. Retrieved from: http://cnx.org/content/m34497/1.1/. [Accessed 17 August 2020]

Spiro M (2003) Academic values and academic work in the era of globalization: the case of Albanian universities. Higher Education in Europe 28(3): 311-313.

Taalas P, Grönlund A, Peterbauer H (Eds.) (2020) Internationalisation in learning and teaching. Thematic Peer Group Report. Learning \& Teaching Paper 9. European University Association.

Teichler U (2009) Internationalisation of higher education: European experiences. Asia Pacific Education Review 10(1): 93-106.

The Camegie Foundation for the Advancement of Teaching (1990) Change trendlines: sizing up colleges and universities. Change 22(6): 35-38.

TREELLLE (2017) Dopo la riforma: Università italiana, università europea? Proposte per il miglioramento del sistema terziario. (After the reform: Italian university, European university? Proposals for the improvement of the tertiary system). Quaderno n.13, Marzo 2017. Retrieved from: http://www.treellle.org/dopo-la-riforma-universit\%C 3\%A0-italiana-universit\%C3\%A0-europea. [Accessed 24 April 2020]

Veugelers R, van der Ploeg F (2009) Reforming European universities: scope for an evidence-based process. In M Dewatripont, F Thys-Clément, L Wilkin (eds.), Higher Education in a Globalized World: Governance, Competition and Performance, 1949. Bruxelles: Editions de l'Université de Bruxelles. 